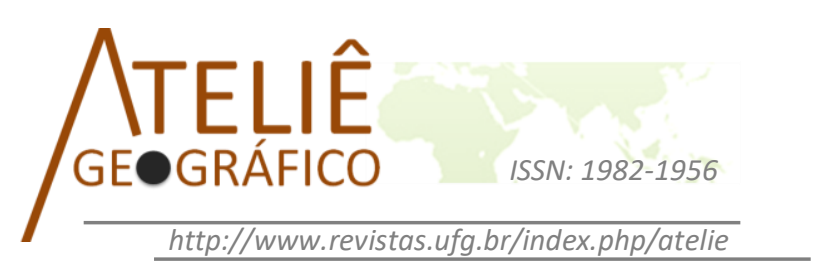

\title{
Indicadores naturais e antrópicos da dinâmica dos movimentos de massa do município de Posse (GO)
}

\author{
Natural and anthropic indicators of the dynamics of mass \\ movements in the municipality of Posse (GO) \\ Indicateurs naturels et anthropiques de la dynamique des \\ mouvements de masse dans la municipalité de Posse (GO)
}

\author{
Lucas Espíndola Rosa \\ lukasespindola@gmail.com \\ Universidade Federal de Goiás \\ Elizon Dias Nunes \\ elizonnunes@gmail.com \\ Universidade Federal de Goiás \\ Luís Felipe Soares Cherem \\ luis.cherem@gmail.com \\ Universidade Federal de Goiás
}

\begin{abstract}
Resumo
A Serra Geral de Goiás é uma cuesta que divide duas paisagens com diferentes fisiografias e ocupações humanas: o Vão do Paranã (GO), a oeste, e a Chapada do Oeste da Bahia (BA), a leste. Do lado goiano, ao longo da frente dessa cuesta são observadas feições originadas de movimentos de massa, cujo início e manutenção têm sido atribuídos a ocupação da Chapada do Oeste da Bahia. Esse trabalho identifica e avalia os fatores controladores (entre naturais e antrópicos) da instalação e manutenção dessas feições ao longo dessa cuesta no município de Posse (GO). Para tanto, é realizada a análise integrada de variáveis climatológicas, geológico-geomorfológicas, pedológicas e da cobertura e uso solo. Os resultados indicam que os movimentos de massa já ocorriam antes mesmo da ocupação agropecuária intensiva do Oeste da Bahia ao final da decada de 1980. A recorrência dos processos tem grande relação com períodos excepcionalmente chuvosos, cuja precipitação mensal acumulada ultrapassa $500 \mathrm{~mm} / \mathrm{mês}$ e também com a diferença lito-estrutural entre as Formações Posse e Serra das Araras.
\end{abstract}

Palavras-chave: morfodinâmica de cuesta; conservação de encostas; impactos ambientais. 


\begin{abstract}
The Serra Geral de Goiás is a cuesta that separates two landscapes with different physiography and human occupation: the Vão do Paranã (GO), on the west, and the Chapada do Oeste da Bahia (BA), on the east. In the Goianian side, along the front of this cuesta, several features resultiong from mass movements are observed, whose initiation and maintenance has been attributed to the occupation of Chapada do Oeste da Bahia. This study aims to identify and evaluate the controlling factors (natural and anthropic) for installation and maintenance of these features along this cuesta in the municipality of Posse (GO). For this purpose, it is carried out the integrated analysis of climatological, geological and geomorphological variables, soil cover and land use. The results indicate that the mass movements have been occoring even before the intensive agricultural occupation of Western Bahia, by late 1980 's. The recurrence of processes is strongly associated to exceptionally rainy periods, where cumulative monthly rainfall exceeds $500 \mathrm{~mm} / \mathrm{month}$ and also to lithostructural differences between Posse Formation and Serra das Araras Formation.

Keywords: cuesta morphodynamics; slopes conservation; environmental impacts.
\end{abstract}

\title{
Resumè
}

La Serra Geral de Goiás correspond à une cuesta qui divise deux paysages de différente physiography et occupation humaine: le Vão do Parana (GO), a l'ouest, et la Chapada Oeste da Bahia (BA), a l'est. Sur le front de cette cuesta, faces à l'ouest, il y a nombreux mouvements de masse, dont la dynamique est généralement attribué à l'occupation de la Chapada do Oeste da Bahia. Le objective est identifier et evaluer les facteurs de contrôle (entre le naturels et les humaine) de l'instalation et de la rétroaction de ces mouvements sur la section central de la cuesta, dans la municipalité de Posse (GO). À cette fin, une analyse integré de les variables climatologique, geologique, geomorphologique, pedologique et de la couverture du sol est performé. Les resultàts montrent que ces processus sont anterieurs à la ocupation humaine de la region, a partir de 1980. La réactivation de ces processus gravitationnels est concomitant à des périodes de fortes précipitation, quand la precipitation cumulée mensuelle arrivé à $500 \mathrm{~mm}$, surtout, où il y a une significative difference litostructurelle entre les Formations Posse et Serra das Araras.

Mots-clés : morphodynamique de cuesta, conservation de pente, impacts environmentals.

\section{Introdução}

O limite entre os estados de Goiás e da Bahia corresponde a uma crista de cuesta, situada na borda da bacia sedimentar sanfranciscana, de litologia predominante arenítica, embasadas pelo Cráton do São Francisco (GASPAR; CAMPOS, 2007). Essa cuesta divide a região do Vão do Paranã (GO) da região do Oeste da Bahia (BA), esta última sob intensa pressão do agronegócio (BRASIL, 2012). Ao longo dessa cuesta, conhecida também como Serra Geral de Goiás, existem inúmeras feições que registram a ocorrência de processos erosivos e gravitacionais associadas à ocupação de seu reverso na Bahia.

Em geral, a morfodinamica das cuestas é, sob condições naturais, controlada por processos gravitacionais e erosivos acelerados, cuja magnitude e frequência são condicionadas pelo contexto climático regional (GOUDIE, 2004). Essa dinâmica já foi tratada em diversos estudos evidenciando aspectos de formação desta unidade geomorfológica (CASSETI, 2005; SALGADO, 2007, BRASIL, 2009). Zancopé et al., (2013) afirmam que as feições erosivas e deposicionais visitadas em campo na porção 
norte da Serra Geral de Goiás, próximo ao Parque Estadual de Terra Ronca, podem ser consequências da ocupação ilegal da área de proteção permanente (APP) ao longo da crista da cuesta no estado da Bahia. Já mais a sul, na região do município de Posse (GO), a natureza dessas feições ainda carece de estudos.

Notadamente, os movimentos de massa (processos gravitacionais) desta região tem por uma das principais variáveis a natureza inconsolidada dos arenitos do Grupo Urucuia, que o torna assim suscetível a processos erosivos e gravitacionais, que por vezes podem atingir algumas dezenas de $\mathrm{km}^{2}$ (Zancopé et al., 2013). Todavia, não foi ainda correlacionado a intensificação destes processos a demais variáveis que possam corroborar com esta situação, como eventos de chuvas intensas, reconhecimento de litologias específicas, fluxos hidráúlicos subsuperficiais dentre outros aspectos. Essa dinâmica tem enormes passívos ambientais na região, destacadamente, assoramento de canais, colmatação de feições cavernícolas e degradação dos recursos hídricos que por vezes também trazem problemas a população local como a mudança dos parâmetros físico-químicos das águas superficiais a jusante. Nesse sentido, o trabalho objetiva avaliar quais são os fatores controladores da morfodinâmica das feições gravitacionais no trecho da cuesta da Serra Geral de Goiás inserida na região do município de Posse (GO).

Para tanto, são analisadas as distribuições espacial e temporal dessas feições antes do avanço da fronteira agrícola, a partir da identificação e classificação dessas feições em uma série temporal de imagens de satélite para os anos de 1990, 1996, 2002, 2008 e 2014, e a respectiva correlação com a expansão da fronteira agrícola nos mesmos anos com eventos de chuvas extremas para cerca dos últimos 40 anos (19772016). A escolha deste recorte temporal se dá pela data de criação de duas das mais representativas unidades de conservação da área de estudo, o Parque Estadual de Terra Ronca em 1990 e a APA Serra Geral de Goiás em 1996, que em hipótese seriam responsáveis pela dimunuiçao da degradação destas encostas. Ademais, relaciona-se a ocorrência dos movimentos de massa a aspectos lito-geomorfológicos e hidrológicos, com consequente observação da relação entre a utilização de poços artesianos e as cicatrizes destes movimentos.

\section{Materiais e método}

\section{Área de estudo}

A área de estudo se localiza em parte das microrregiões administrativas do Vão Paranã (GO) e Oeste Baiano (BA), correspondendo a parte dos municípios de Posse e Guarani de Goiás, no estado de Goiás, bem como a Correntina no estado da Bahia, conforme Figura 1. Esta área é considerada como a última fronteira agropecuária no estado de Goiás, notabilizada pela transição entre a região do agronegócio baiano e o polo urbano de Brasília (BARREIRA, 2002; HAESBAERT, 
1996). Em um senso mais amplo, a área de estudo está inserida na porção do Vão do Paranã (GO) em um dos mais representativos remanescentes do bioma Cerrado de Goiás, evidenciados por zonas de tensão ecológicas, que em síntese se exibem como a transição entre áreas savânicas e florestais deste mesmo bioma (KLINK; MACHADO, 2005; RIBEIRO; WALTER, 2008; OLIVEIRA, 2014).

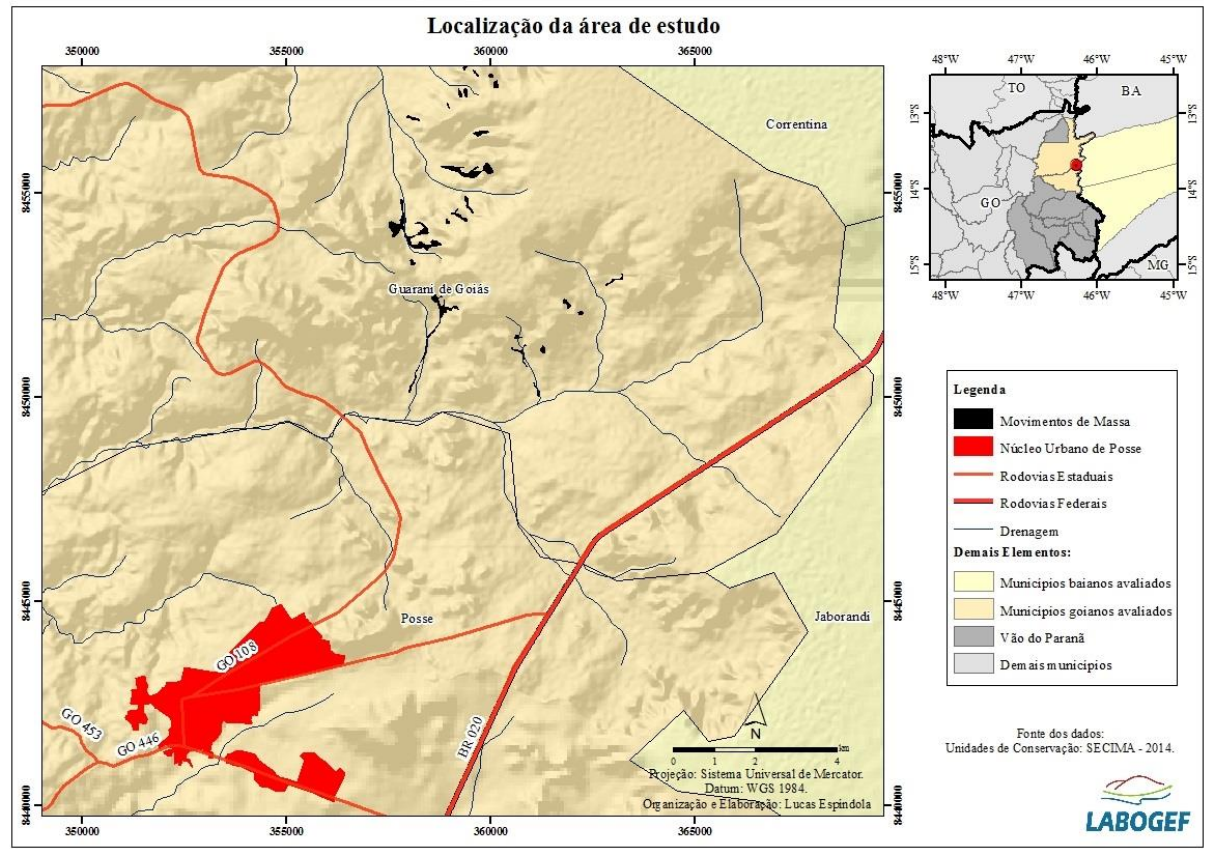

Figura 1: Localização da área de estudo. Elaborado pelos autores.

O Vão do Paranã é uma das regiões no estado de Goiás em que se é permitido notar grandes remanescentes de mata seca, ou floresta estacional decidual, fitofisionomia esta que apresenta estrita relação com alguns condicionantes físicos, entre eles solos ricos em bases trocáveis e afloramentos rochosos calcários, mas que também são observados nos tálus das escarpas da Serra Geral de Goiás cujo o material é predominantemente arenítico (SHINZATO; 1998; HERMUCHE, 2010). A região do Vão do Paranã é composta predominantemente por rochas carbonáticas relativas ao Grupo Bambuí, onde se situam as mais representativas feições cavernícolas do estado de Goiás, que por vezes são parcialmente colmatadas pelas cicatrizes gravitacionais.

A Chapada do Oeste da Bahia corresponde a porção oriental da área estudada, sendo composta predominantemente por rochas do Grupo Urucuia (mesozóico cretáceo) que exibem uma divisão em duas Formações: Posse e Serra das Araras, conforme Figura 2. A primeira apresenta-se subdividida em duas fácies, onde a 
primeira face é constituída por arenitos muito finos, finos, médios e bem selecionados, enquanto a segunda face apresenta ocorrências de materiais argilosos e feldspáticos menos maduros ante a primeira, estando relacionados a ambientes eólicos. A formação geológica da Serra das Araras está relacionada a ambientes fluviais pretéritos de canais entrelaçados, consistindo de bancos de 0,5 a $2 \mathrm{~m}$ de espessura, ocorrendo arenitos, argilitos e conglomerados avermelhados e se encontram sobrepostos a Formação Posse. Originado em ambientes semelhantes ao Grupo Urucuia e pertencentes a bacia sedimentar sanfranciscana, a área de estudo exibe ainda os arenitos do Grupo Santa Fé e Grupo Areado, ambos do paleozóico, mas bastante restritos e posicionados predominantemente próximos ao núcleo urbano de Posse (GO) (CAMPOS; DARDENNE, 1997; BRASIL, 2007; LACERDA et al., 2008).

Nas intermediações da BR-020, na mesma região, a espessura dos arenitos do Grupo Urucuia é estimada em aproximadamente $120 \mathrm{~m}$, avaliados a partir do contato basal com os afloramentos do Grupo Bambuí, sotoposto ao Grupo Urucuia, que tem neste ponto sua cota estimada em cerca de 800 m (BRASIL, 2007). Contudo, há variação na espessura da unidade Urucuia, haja visto que a crista da escarpa erosiva apresenta uma cota com cerca de $1.050 \mathrm{~m}$, bem como exibem cotas diferenciais à medida que se encontram em bacias hidrográficas com níveis de base distintos, sendo estes valores de cota estimados para uma melhor diferenciação. Ademais, observa-se também como fator limitante para o estabelecimento de cotas-padrão algumas falhas normais observadas, evidenciadas pelos processos de tectônica de ruptura, identificados pelos diferentes patamares nas discordâncias erosivas entre as Formações Serra das Araras e Posse, conforme Figura 2. Há também relatos da Formação Geribá, presente no Grupo Urucuia, que tem por sua constituição rochas pelíticas intercaladas com arenitos finos, que além de carecer de mais estudos não são observados no estado de Goiás (BRASIL, 2007; LACERDA et al., 2008).

Quanto ao clima a área de estudo está inserida no clima tropical sub-úmido (Aw), segundo a classificação climática de Köppen. Esta zona climática é marcada por duas estações bem definidas, sendo uma chuvosa que vai de outubro a abril, e outra seca, de maio a setembro (NIMER, 1979). Ademais, o município de Posse é onde se encontra a única estação meteorológica do INMET (Est. 83332) para região do Vão do Paranã e consequentemente para área de estudo evidenciando cerca de $1.400 \mathrm{~mm}$ de média de chuva registrados ao ano. 


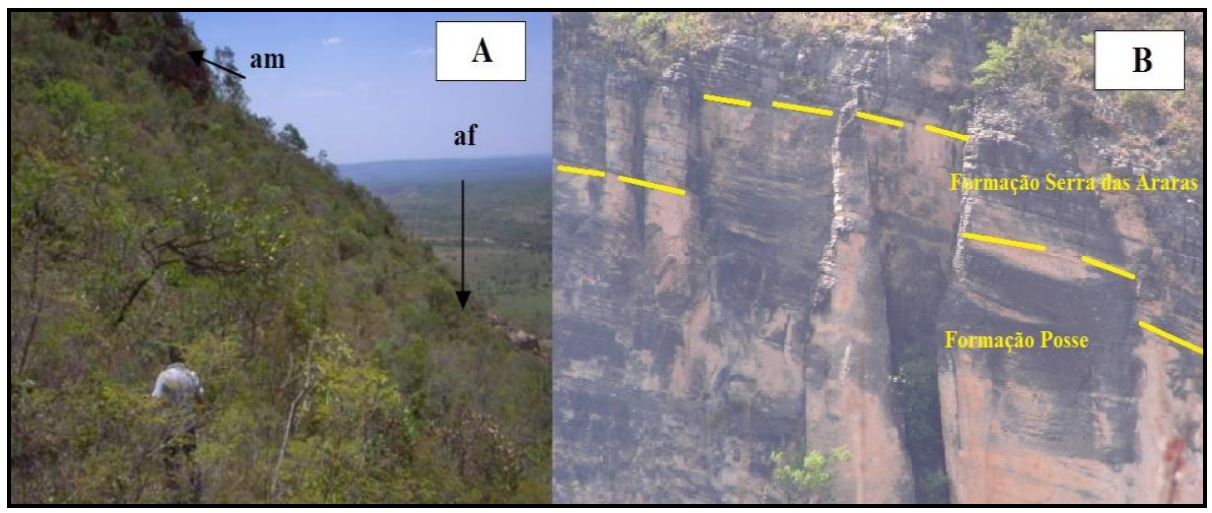

Figura 2: Arenitos do Grupo Urucuia. Na Figura "A" são evidenciados a discordância erosiva entre os arenitos das formações Posse e Serra das Arras em cota 943m. Os arenitos da Formação Serra das Araras (am) apresentam granulometria de média à grosso, com extratificação cruzada acanalada, enquanto os arenitos da Formação Posse (af) são finos com extratificação cruzada de grande porte, conforme Figura "B".

Fonte: Figura "A" BRASIL (2007) e Figura "B" Autores (2016).

\section{Procedimentos Metodológicos}

A análise dos movimentos de massa exibe como referencial teóricometodológico a classificação quanto à forma (corrida; escorregamento, rotacional e planar; e queda de blocos) e o período de observação da última dejeção (antiga, atual e recente), (FERNANDES; AMARAL, 2000; ZANCOPÉ et al., 2013), conforme sintetizado no Quadro 1.

A identificação dos indicadores naturais e antrópicos dos movimentos de massa consistiu inicialmente na correlação espacial entre as feições mapeadas e as caracterísitcas litológicas, (BRASIL, 2007), (LACERDA FILHO et al., 2008), (GASPAR; CAMPOS, 2007); geomorfológicas (LATRUBESSE et al., 2006 ); hidrológicas (GASPAR; CAMPOS, 2007), (BRASIL, 2012), e pedológicas BRASIL (1982).

Adicionalmente a esses primeiros mapas de síntese foram correlacionados em sua dimensão temporal com a ocorrência, bem como frequência dos eventos pluviométricos. Em seguida, buscando os indicadores antrópicos, correlacionou-se os mapas de síntese dos indicadores naturais com a dinâmica da cobertura e uso do solo verificada na área no período entre 1990 a 2014. 
Quadro 1: Classificação dos movimentos de massa quanto à forma e o período de observação.

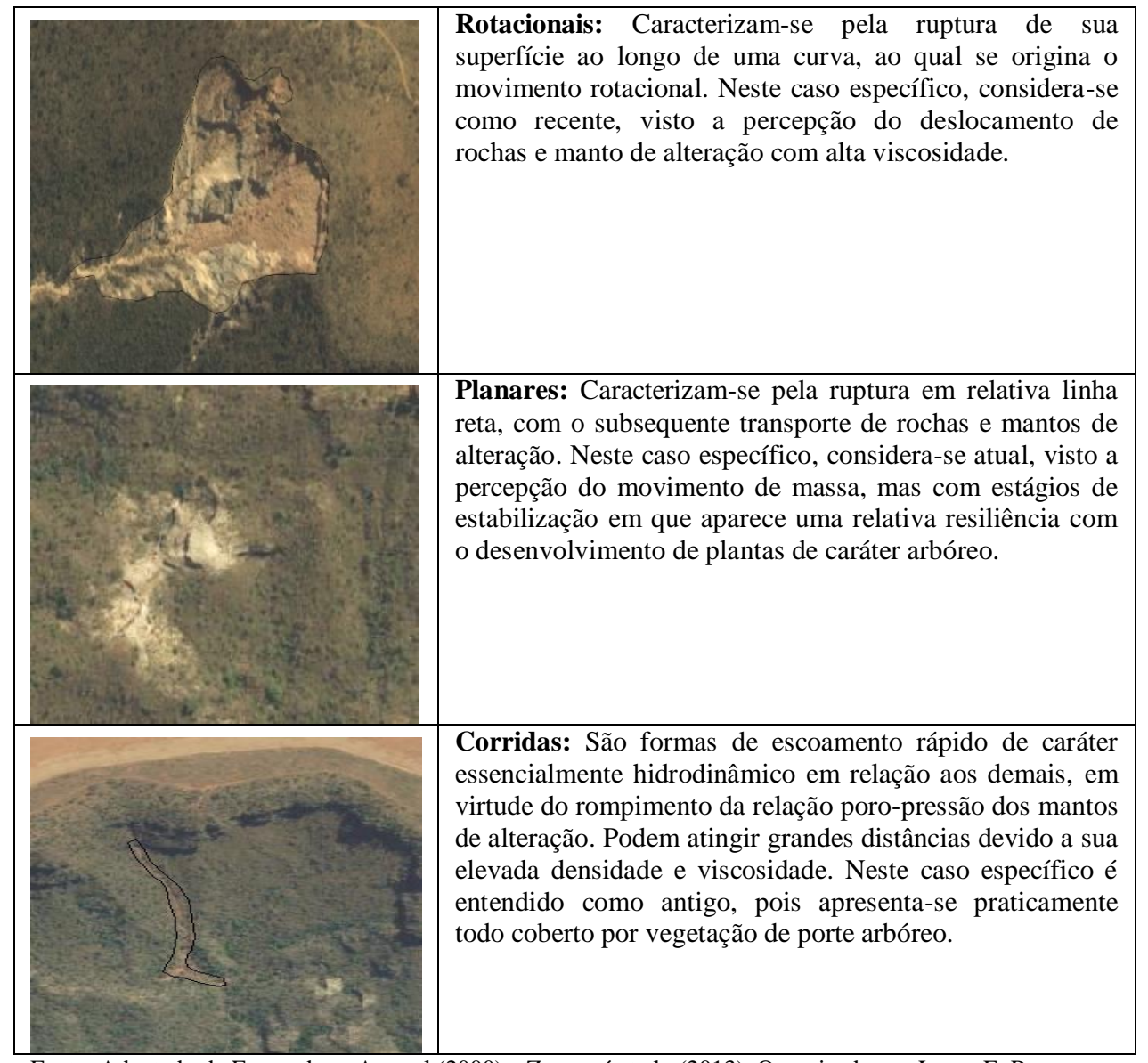

Fonte: Adaptado de Fernandes e Amaral (2000) e Zancopé et al., (2013). Organizado por Lucas E. Rosa.

Para melhor precisão e acurácia dos materiais cartográficos que contêm informações litológicas, geomorfológicas pedológicas da área de estudo, foram realizados um refinamento baseado nas informações morfométricas do MDE de $30 \mathrm{~m}$ disponibilizados pelo TOPADATA, bem como alguns artigos pertinentes a temática que apresentam a descrição de afloramentos, contatos litológicos, direção de fluxos hídricos entre outras informações, que substanciaram a avaliação destas feições erosivas (VENEZIANI; ANJOS, 1982; BRASIL, 2007; GASPAR; CAMPOS, 2007; BRASIL, 2012; NUNES, 2015).

Para o mapeamento dos movimentos de massa foram utilizadas imagens SPOT 4 coloridas e com resolução espacial de 2,5 metros referentes ao segundo semestre de 2011 e primeiro semestre de 2012, e Geoeye também coloridas com resolução espacial 
de 0,5 metros referentes ao segundo semestre de 2013. A fim de padronizar o processo de inspeção visual do terreno na escala 1:3.000 dividiu-se a área de estudos em uma malha retangular medindo $1 \times 1,5 \mathrm{~km}$ de latitude e longitude, respectivamente.

Dessa forma, a varredura, o mapeamento e a inspeção visual dos movimentos de massa da área de estudo podem ser realizados em uma mesma escala, aproveitando o detalhamento máximo proporcionado pelas imagens, sendo que as feições foram classificadas em: corrida, rotacional e planar conforme evidenciado no quadro 1 . Outras classificações como queda de blocos não foram consideradas, haja visto a natureza do material e do fenômeno não observado com contundência na área de estudo. Estes movimentos são mais expressivos na região de "Mares de Morros" e se constituem de litologias predominantes como granitos e gnaisses, muitas das vezes associados a áreas urbanas, mas podendo ocorrem em áreas rurais e sob diferentes materiais de alteração (FERNANDES; AMARAL, 2000, GUERRA et al., 2007).

De forma complementar procedeu-se a validação em campo de várias feições mapeadas, a fim de garantir maior fidedignidade entre a assinatura espectral na imagem e o fenômeno em campo.

Para o mapeameto da cobertura e uso do solo utilizou-se de imagens do sensor TM do satélite LANDSAT 5, composição RGB 543 para os anos de 1990, 1996, 2002 e 2008, e do sensor OLI do satélite LANDSAT 8, composição RGB 654 para o ano de 2014, ambas coloridas e com resolução espacial de 30 metros de ponto e órbita 220/70. Para tanto, procedeu-se a classificação supervisionada, com a análise pixel a pixel e por máxima verossimilhiança. Adicionalmente é executada a inspeção visual, dando especial destaque para as manchas de solo exposto, bem como sua permanência e crescimento do entorno imediato, cujo surgimento, para algumas, remonta ao ano de 1990 ou período anterior, que. nestes casos. foram mapeados por poligonização direta.

Para avaliação da série temporal de pluviometria utilizou-se os dados provenientes da estação meteorológica - 83332 do INMET localizada no município de Posse (GO) correspondente ao período de 1976-2016. Por meio desses dados observouse as variáveis precipitação acumulada diária e mensal; a frequência e magnitude dos eventos pluviométricos para o período analisado.

Destaca-se que foram considerados nesta classificação, a gênese do movimento, visto que, em alguns momentos, os movimentos rotacionais, planares e de corrida se coalescem podendo divergir quanto a classificação. Na avaliação das imagens LANDSAT foram considerados apenas os movimentos recentes, visto que, nestas imagens são permitidos observar a carga detrítica em condições de baixa resiliência, semelhantes ao solo exposto (ZANCOPÉ et al., 2013).

\section{Resultados e discussão}

A análise dos movimentos de massa permitiu constatar uma diminuição areal entre 1990 e 2008, com retomada do crescimento em 2014, evidenciando que as 
mesmas cicatrizes apresentam diferentes pulsos de dejeção de sedimentos. Contudo, nota-se que pouco mudou em relação à quantidade total dos movimentos, onde foram observados 29 no ano de 1990, e 25 no ano de 2014, conforme Tabela 1.

Tabela 1: Movimentos de massa no município de Posse (GO).

\begin{tabular}{|c|c|c|c|c|c|c|c|c|}
\hline $\begin{array}{c}\text { Ano de } \\
\text { observação }\end{array}$ & $\begin{array}{c}\text { Qtde. de } \\
\text { Movimentos }\end{array}$ & $\begin{array}{c}\text { Área - } \\
\text { Rotacional }\end{array}$ & $\mathbf{( \% )}$ & $\begin{array}{c}\text { Área - } \\
\text { Corrida }\end{array}$ & $\begin{array}{c}\text { A\%) } \\
\text { Alanar }\end{array}$ & $\begin{array}{c}(\%) \\
\text { Área total } \\
(\mathbf{H A})\end{array}$ \\
\hline 1990 & 29 & 294,32 & 77,70 & 48,88 & 12,90 & 35,59 & 9,40 & 378,79 \\
\hline 1996 & 31 & 77,5 & 42,51 & 23,29 & 12,77 & 81,54 & 44,72 & 182,33 \\
\hline 2002 & 29 & 79,47 & 80,09 & 19,75 & 19,91 & 0 & 0 & 99,22 \\
\hline 2008 & 27 & 62,11 & 80,67 & 14,88 & 19,33 & 0 & 0 & 76,99 \\
\hline 2014 & 25 & 95 & 85,32 & 16,34 & 14,68 & 0 & 0 & 111,34 \\
\hline
\end{tabular}

Fonte: Calculado em ambiente SIG.

No primeiro ano, 1990, o estudo percebeu que o fenômeno ocupava uma área de 378,79 hectares, sendo as feições rotacionais responsáveis por cerca $78 \%$ das cicatrizes observadas, enquanto na avaliação subsequente, em 1996, esta feição era responsável por $42,51 \%$ da área, sendo neste ano superada pelas feições planares. Já nos anos de 2002, 2008, e 2014 retoma-se o predomínio dos movimentos rotacionais, onde os movimentos planares entram em "equilíbrio", visto a percepção do processo de resiliência nestes locais, conforme Figura 3.

Quanto ao uso e cobertura, o avanço e aumento da ocupação agropecuária em direção à escarpa, pouco contribuiu para o avanço dos movimentos de massa, visto a sua redução areal proporcionada entre 1996-2008, apesar do crescimento na utilização das terras no reverso da escarpa.

Destaca-se que, entre os movimentos de massa observados, o predomínio está nos arenitos da unidade geológica Grupo Urucuia (Formação Posse e Serra das Areias) (LACERDA FILHO et al., 2008). Observa-se ainda que as feições mais contundes estão na Formação Posse, visto a natureza destes arenitos que são pouco coesos por não apresentarem em seus agentes cimentantes materiais argilosos, sendo que sua litologia é composta predominantemente por arenitos muito finos, finos, médios, quartzosos e bem selecionados. 


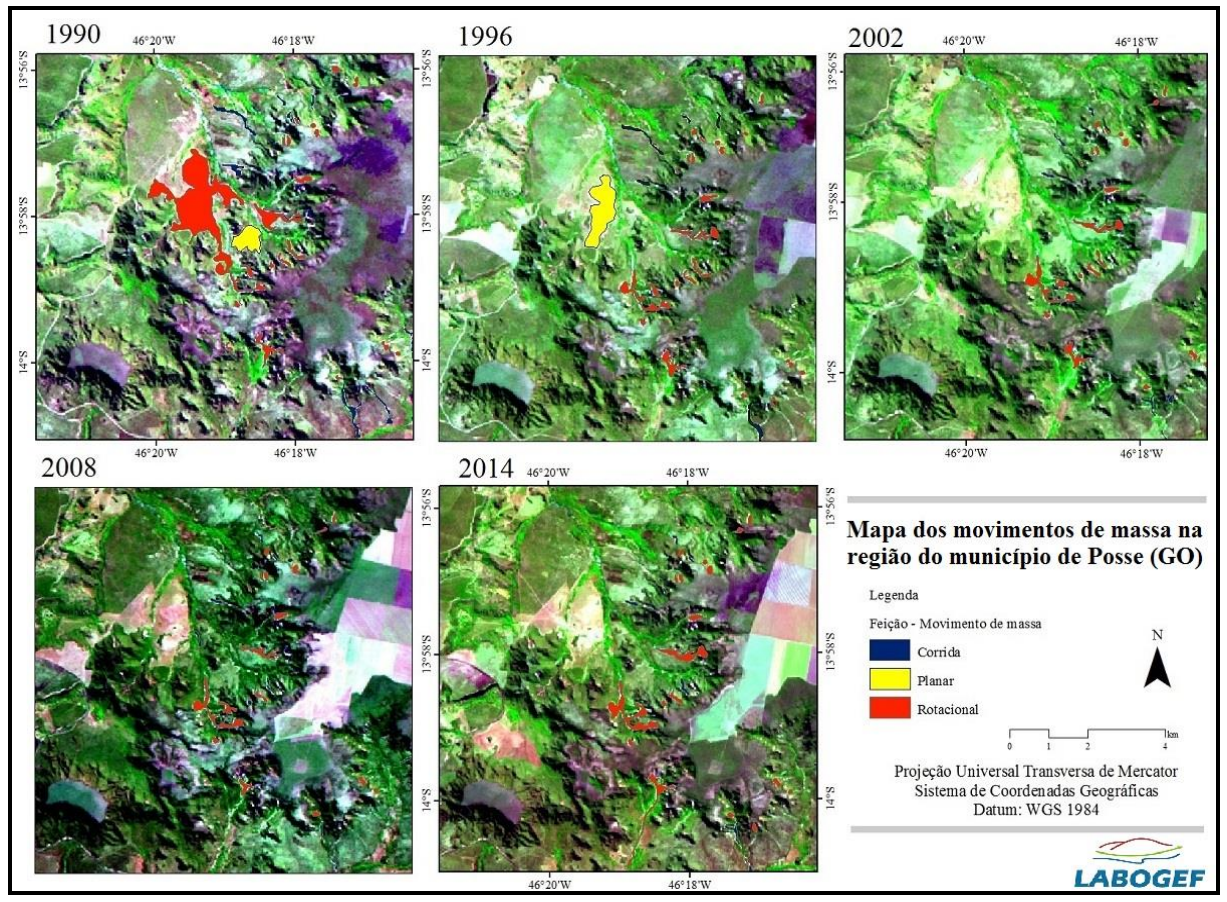

Figura 3: Evolução dos movimentos de massa ativos entre 1990 e 2014. Fonte: Imagens LANDSAT 5 TM (RGB 543) e 8 OLI (RGB 654).

Já na Formação Serra das Araras apresentam-se movimentos mais restritos, haja visto que são compostos por bancadas de areníticas entre de 0,5 a $2 \mathrm{~m}$ com associações de argilitos e conglomerados avermelhados e lateritas, que possuem uma maior coesão pelos os agentes cimentantes em suas estruturas. (LACERDA FILHO op.cit).

Destaca-se que apesar deste reconhecimento observado quanto a constituição e resistência dos materiais areníticos auxiliam na identificação das suscetibilidades, as mesmas pouco influenciam quando o aporte de energia sobre estas encostas apresentam uma grande entrada, como em caso de chuvas torrenciais, por exemplo. Estas condições se mantêm em situações de semelhantes encostas em relação a declividade e curvatura, perdendo sua eficácia em situações extremas, em caso de intensas precipitações.

Além disso, a região de estudo apresenta um sistema de aquífero subterrâneo poroso regional, o Urucuia. Este sistema apresenta limite divergente à Serra Geral de Goiás e demais bacias hidrográficas, evidenciado por uma linha de ruptura quase paralela e próxima à BR-020, em que as águas subterrâneas direcionam suas linhas de fluxo em sentido E-W, em direção a Serra Geral de Goiás (GASPAR; CAMPOS, 2007; 
BRASIL, 2012). Ademais, indica-se que toda contribuição das águas superficiais provém do fluxo de base subterrâneo, o que pode acarretar no aumento na incidência de movimentos (BRASIL, 2012).

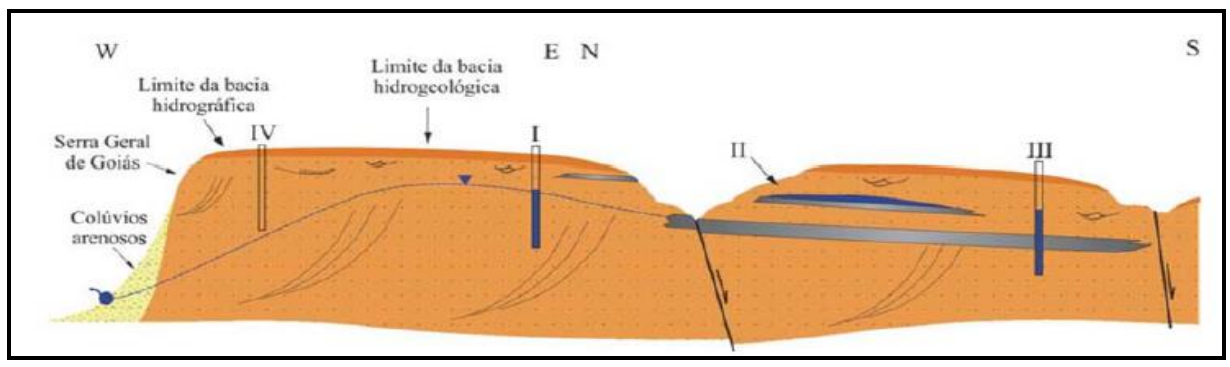

Figura 4: Limites da bacia hidrogeológica do Urucuia e das bacias hidrográficas cuja suas nascentes ocorrem escarpa da Serra Geral de Goiás.

Fonte: Gaspar e Campos (2007) citado por BRASIL (2012). Adaptado.

Em uma análise temporal de trinta e sete anos, observa-se que o município de Posse (GO) apresenta uma precipitação média anual de aproximadamente $1.400 \mathrm{~mm}$, sendo que o ano de 1983 apresenta a maior precipitação média registrada, com 1.931,4 $\mathrm{mm}$ de chuva. Já o ano de 2007, exibe a menor média com 820,8 $\mathrm{mm}$ ano. Quanto a distribuição, as chuvas se concentram principalmente nos meses de dezembro, março, fevereiro e novembro respectivamente, demonstrando resultados similares aos encontrados por Luiz (1997) na região do Vão Paranã. Ademais, a principal concentração de chuvas ocorre no mês de dezembro no município de Posse (GO), apresentando um domínio de 54,05\% dos dados amostrais observados, indicando que os movimentos de massa observados nas imagens satelitárias no período de estiagem (maio-agosto) podem ter apresentado influência das fortes chuvas obtidas nos meses pretéritos, sobretudo o de dezembro, marcados em negrito no eixo "Y", conforme Figura 4.

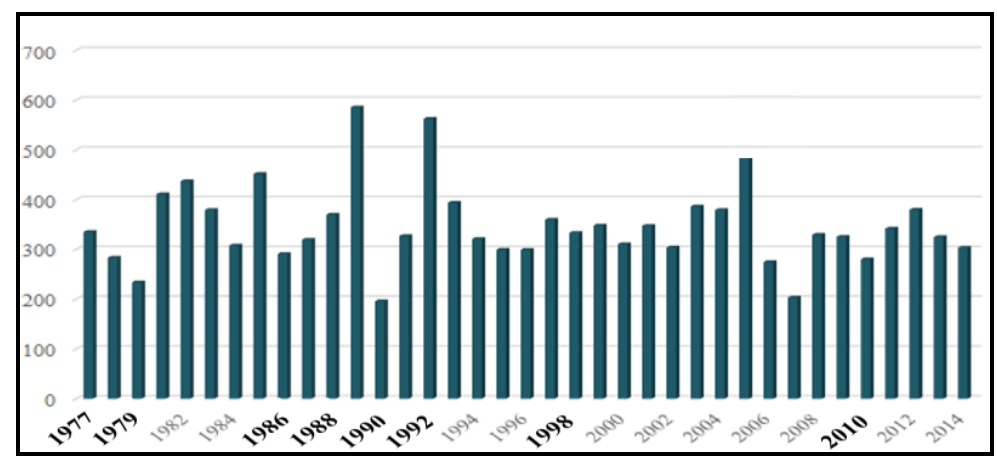

Figura 2: Principal concentração de chuva mensal em milímetros no município de Posse (GO) entre 1977-2014. Fonte: INMET, 2016. 
A partir da observação dos dados de chuva, constatou-se que no mês de dezembro do ano de 1989, ocorreu um acumulado de 585,2 $\mathrm{mm}$ de chuva, sendo o maior acúmulo observado no período amostral de trinta e sete anos (Figura 2). Essa concentração de precipitação pode ter influenciado na reativação dos movimentos de massa do município mapeados para o ano de 1990, que aliado as condicionantes já apresentadas, podem ter sido responsáveis pela grande entrada de energia no sistema. Nos anos subsequentes, observa-se uma tendência de melhor distribuição e diminuição da concentração das chuvas, sendo o ano de 2007, no mês de dezembro, responsável pela menor das maiores concentrações de chuvas anuais com 203,4 mm de chuva.

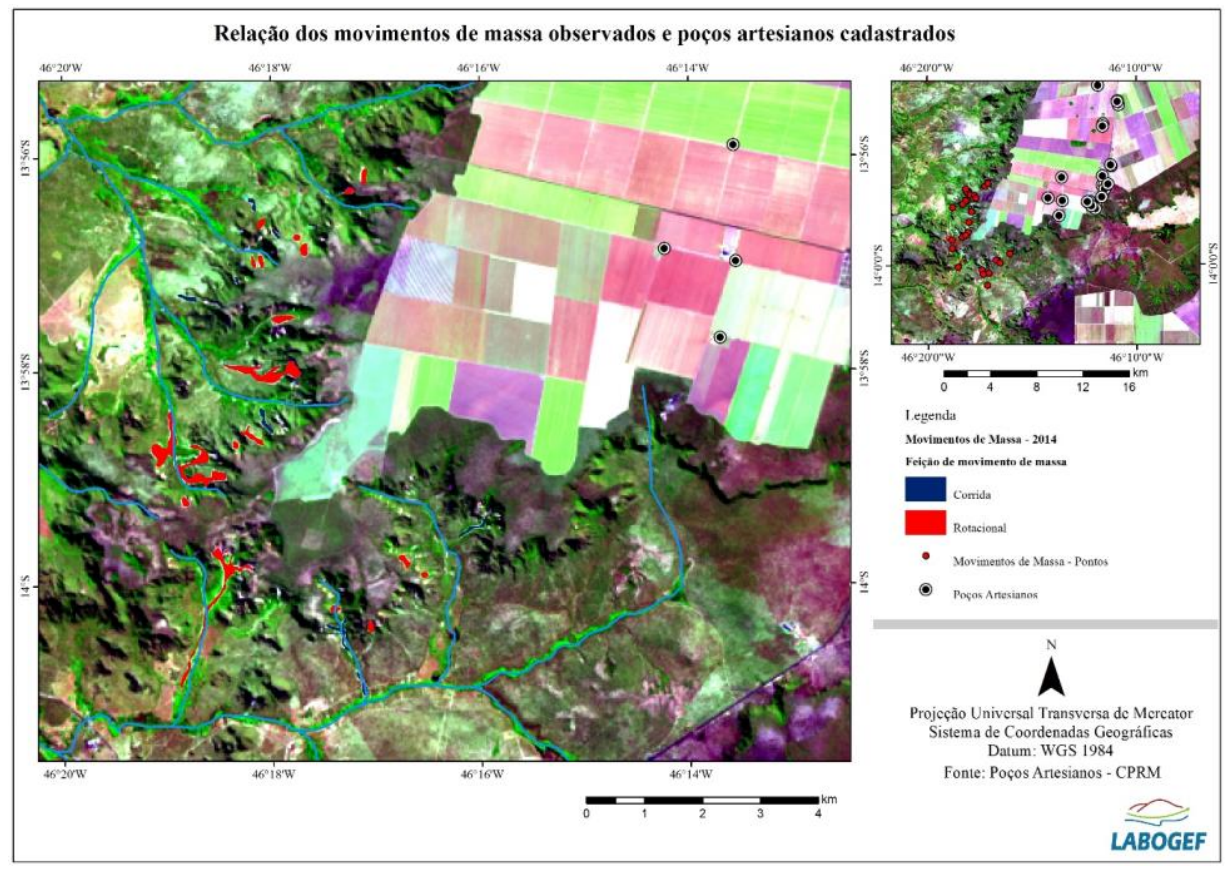

Figura 5: Relação entre poços artesianos e movimentos de massa. Fonte: Imagens LANDSAT 5 TM (RGB 543) e 8 OLI (RGB 654).

A situação de fragilidade destas cicatrizes gravitacionais podem ser reforçadas pelo grande uso de águas do Sistema Aquífero Urucuia - SAU, tendo em vista que no município de Correntina (BA) que se posiciona a montante destas feições gravitacionais apresenta 247 poços artesianos registrados, ante a 2 poços no município de Posse (GO) e Guarani de Goiás (GO). Quando observados a espacialização dos poços artesianos observa-se uma grande quantidade destes poços no setor em que ocorrem estes movimentos, onde 4 poços apresentam uma distância aproximada de 7 km da escarpa, conforme Figura 5. 


\section{Considerações finais}

A análise dos fatores controladores dos processos gravitacionais evidenciou que a cobertura e uso, especialmente a expansão da fronteira agrícola do Oeste da Bahia, exibe baixa relação com a ocorrência e reativação de movimentos de massa na cuesta da Serra Geral de Goiás. Por outro lado, o início e reativação das feições erosivas e gravitacionais teve alta relação com os meses de alta concentração de pluviosidade. Desta maneira, entende-se que a correlação espacial entre a magnitude e distribuição das chuvas, litologias mais suscetíveis (Formação Serra das Araras) e direcionamento dos fluxos subsuperficiais em sentido à escarpa da Serra Geral tem propiciado a formação destes movimentos de massa.

\section{Referências}

BARREIRA, C.C.M.A. Vão do Paranã: a estruturação de uma região. Brasília: Ministério da Integração Nacional, Universidade Federal de Goiás, 2002. 320 p.

BRASIL. Caracterização geológica e Geométrica dos Aquíferos - Revisão Geológica e Levantamento Geofísico. Rede Cooperativa de Pesquisa UFBA - CPRM. Brasília: 2007.

Manual técnico de Geomorfologia. IBGE Instituto Brasileiro de Geografia e Estatística, MPOG. Rio de Janeiro: : 2.ed. 2009.

Relatório diagnóstico Sistema Aquífero Urucuia bacia sedimentar Sanfranciscana. CPRM Serviço Geológico do Brasil, MME. Brasília: v.10, 2012. Instituto Nacional de Meteorologia - INMET. Banco de Dados Meteorológicos para Ensino e Pesquisa. Disponível em: http://www.inmet.gov.br Acesso em 02 set. 2016.

CASSETI, V. Geomorfologia. Goiânia: FUNAPE, 2005. http://www.funape.org.br/geomorfologia . Acesso em 02 set. 2016.

FERNANDES, N. F.; AMARAL, C,P. Do. Movimentos de Massa: Uma abordagem geológico -geomorfológica. In: GUERRA, A. J. T.; CUNHA, S. B. (Org.). Geomorfologia e Meio Ambiente. Rio de Janeiro: 3.ed. Bertrand Brasil, 2000. p. 123194.

GASPAR, M.T.P; CAMPOS J.E.G. O sistema aquífero Urucuia. Revista Brasileira de Geociências. n. 37, v.4 (suplemento), p. 216 -226. São Paulo: 2007.

GOUDIE, A.S. Encyclopedia of Geomorphology. International Association of Geomorphologists. Londres: v.1. 1.ed. 2004. 
HAESBAERT, R. Gaúchos e Baianos no "Novo" Nordeste: entre a Globalização e a Reinvenção das Identidades Territoriais. In: Castro, I. GOMES, P.C.Da..C.; CORREA, R.L. Brasil: questões atuais da reorganização do território. Rio de Janeiro: Bertrand Brasil, 1996.

HERMUCHE, P.M. Modelagem da paisagem da Floresta Estacional Decidual no Vão do Paranã, Goiás. Goiânia: UFG. Tese. 2010. 137 p.

KLINK, C.A., MACHADO, R.B. A conservação do Cerrado brasileiro. Megadiversidade. v.1, n.1, 2005.

LACERDA FILHO, J. M., (Coord). GOIÁS (Estado). Secretaria de Indústria e Comércio. Superintendência de Geologia e Mineração. Geologia do estado de Goiás e Distrito Federal. Goiânia: 2008.

LANDSAT. Disponível em: http:// www.usgs.gov Acesso em: 3 maio 2016.

LUIZ, G.C. Análise da distribuição pluviométrica e as condições para o processo de uso e ocupação do solo - Região do Vão do Paranã-GO. Boletim Goiano de Geografia. Goiânia: v.17, n.1, p. 33-45, jan/jun. 1997.

NIMER, E. Climatologia da região Centro Oeste do Brasil. Introdução à Climatologia Dinâmica. Revista Brasileira de Geografia. v.34, n.4, p.3-29. 1972.

NUNES, E.D. Modelagem de processos erosivos hídricos lineares no município de Mineiros - GO. Goiânia: UFG. Tese. 2015. 244 p.

OLIVEIRA, I.J.De. Chapadões descerrado: relações entre vegetação, relevo e uso das terras em Goiás. Boletim Goiano de Geografia. Goiânia: v.34, n.2. p. 311-336, mai/ago. 2014.

RIBEIRO, J.F.; WALTER, B.M.T. Fitofisionomias do bioma Cerrado: os biomas do Brasil. In: Cerrado: ambiente e flora. Planaltina: EMBRAPA, 2 ed. 2008 p.89-116.

SALGADO, A.A.R. Superfícies de aplainamento: antigos paradigmas revistos pela ótica dos novos conhecimentos geomorfológicos. GEOografias: Belo Horizonte: v.3, n.1, p. 64-78, jan/jun. 2007.

SHINZATO, E. O carste da área de proteção ambiental de Lagoa Santa (MG) e sua influência na formação dos solos. (Tese Doutorado). Universidade Estadual do Norte Fluminense, Centro de Ciências e Tecnologias Agropecuárias. 1998.

VENEZIANI, P.; ANJOS, C.E. Metodologia de interpretação de dados de Sensoriamento Remoto e aplicações em Geologia. São José dos Campos: INPE, 54 p., 1982. 


\section{ZANCOPÉ, M.H.C; MOMOLI, R.S.; BAYER, M. Movimentos de massa nas nascentes do Rio São Vicente, Parque Estadual "Terra Ronca". Estudo técnico - SEMARH. Goiânia: 2013.}

\section{Lucas Espíndola Rosa}

Geógrafo e Mestrando em Geografia pela Universidade Federal de Goiás. Atualmente é Técnico em Mineração do Laboratório de Geomorfologia, Pedologia e Geografia Física LABOGEF no Instituto de Estudos Socioambientais.

IESA, Campus Samambaia, Conjunto Itatiaia, Caixa Postal 131, Cep: 74001-970 Goiânia/GO.

E-mail: lukasespindola@gmail.com

\section{Elizon Dias Nunes}

Geógrafo, Doutor em Geografia pela Universidade Federal de Goiás. Atualmente é Geógrafo do Laboratório de Geomorfologia, Pedologia e Geografia Física - LABOGEF no Instituto de Estudos Socioambientais.

IESA, Campus Samambaia, Conjunto Itatiaia, Caixa Postal 131, Cep: 74001-970 Goiânia/GO.

E-mail: elizonnunes@gmail.com

\section{Luís Felipe Soares Cherem}

Bacharel em Geografia e mestre em Análise e Modelagem de Sistemas Ambientais pela Universidade Federal de Minas Gerais, doutor em Ciências Naturais pela Universidade Federal de Ouro Preto e doutor em Geociências do Meio Ambiente pela Universidade de Aix-Marselha, França. Atualmente é Professor Adjunto III da Universidade Federal de Goiás, pertencendo ao corpo de docentes permanentes do Programa de Pós-graduação em Geografia da UFG/IESA.

E-mail: luis.cherem@gmail.com

Recebido oara publicação em maio de 2016. Aprovado para publicação em agosto de 2016. 